\title{
Dynamic Occupation-Replenish Balance Theory of Coal Village Relocation based on PSO Algorithm
}

\author{
YANG Yao-qi ${ }^{1}$, Wang Zheng $^{2}$, Li Sucui ${ }^{2}$ Yang Yuanpei $^{1}$ \\ ${ }^{1}$ Peking University School of Economics, Beijing 100083, China \\ ${ }^{2}$ Land Reclamation and Ecological Reconstruction,China University of Mining and Technology
} (Beijing), Beijing 100083,China

\begin{abstract}
Keywords:dynamic occupation-replenish balance;PSO;coal village;relocation planning Abstract. Long-term coal mining under villages in our country has caused subsidence and deformation of land surface, large areas of farmland and houses has been damaged and the villages are no longer liveable. It is imminent to find a reasonable villages relocation method. This study improved traditional "occupation first replenish later" and "replenish first occupation later" theory, proposed a new coal village relocation theory, the dynamic balance between occupation and replenish. This new theory can solve the problem of land occupation, and pressure the reclamation project in coal village. The PSO algorithm was used to optimize the relocation planning. This new theory has been verified by the instance of Longgu mine. The result showed that, the dynamic balance between occupation and replenish theory can effectively reduce the acquisition land area and resolve the contradiction between people and land using; The PSO algorithm can maximize the surplus land area and the per capita building land area of farmer.
\end{abstract}

\section{Introduction}

For the problem on the shortage of land in coal villages, many scholars have studied the relevant land policy and relocation ideas[1-3]. Currently there has been two theoretical approaches,"occupation first replenishment later" and "replenishment first occupation later", on relocation land. But problems such as difficulties in land occupation, land replenishment and relocation process still exist. This study proposed a dynamic occupation-replenishment balance theory of relocation.With the moment of new rural construction, it achieves the land targets in the enclosed space of coal mining area, meets the relocation land targets in coal village, seeks to maximize the protection and use of land, and comprehensively promotes the smooth relocation in coal village. Then according to the objectives and qualifications of coal village relocation,it builds the mathematical model of dynamic occupation-replenishment balance theory of coal village relocation. PSO algorithm, an intelligent optimization algorithm based on population, is proposed by Kennedy and Eberhart in 1995[4]. With the simple operation, high precision and fast convergence, it is widely used in the field of nonlinear optimization. PSO algorithm is used in this study to optimize the land occupation area in each relocation, land replenishment area and reclamation methods. This study explores a theoretical path to coordinate exploitation on coal resources and sustainable development of land in coal village, providing the theoretical support to energy security in plain coal base and stable development of society.

\section{Dynamic"Occupation-Replenishment"Balance Theory of Coal Village Relocation}

Cultivated land occupation-replenishment balance means that our nation adopted the occupied land replenishment system,which is stipulated in "Land Management Law". In this system,land occupation for non-agricultural construction after approval should follow the principle "same amount of compensation", and cultivated land substantially in same quantity and quality. This system is an important initiative to keep the area of cultivated land above 18 million acres[5]."Occupation" means cultivated land occupation which generally refers to the occupation for construction; "replenishment" means cultivated land replenishment which generally refers to the replenishment by means of land development, land consolidation and land reclamation; "occupation-replenishment balance" means keeping the size and quality roughly same . 
In 2004,the concept that land increases and decreases should be linked to each other was proposed in "the State Council on Deepening the Reform strict land management". Then the land pattern of "occupation first replenishment later" was becoming widely promoted. The biggest problem of "Occupation first replenishment later" is the difficulty in replenishment.With the lack of reserve resources in coal mining subsidence area and a variety of objective reasons,quantity imbalances such as occupying land without replenishing and occupying more than replenishing is likely to be caused during land replenishment,and the quality imbalances such as occupying rich land with poor land replenished and occupying cultivated land with other kinds replenished as well[6].Currently, in order to protect cultivated land and food security, local government has tended to use the approach "occupation first replenishment later"except for a few special circumstances.

2008, the ministry of land and resources formulated and issued the "CPC Central Committee on rural reform and development of several major issues", highlighting the concept"replenishment first occupation later";strict enforce of "replenishment first occupation later" was further required in "to strengthen the control on the implementation of the most stringent farmland protection system" in 2014. This method can effectively solve the problem of unbalanced land. However, because of the particularities of coal mining subsidence ,the amount of land used to "replenishment first" is very limited. The demand for relocation land can not be met timely, which tends to cause difficulties in relocation and seriously affect the progress of coal mining and relocation schedule. In addition, circumstances in coal villages are special. Many houses have been damaged seriously. Relocation is so urgent for the protection of personal and property safety of the villagers that there is not enough time for "replenishment first".

This study, based on the concepts "occupation first replenishment later" and "replenishment first occupation later", proposes dynamic "occupation-replenishment" balance theory. The thoughts to regulate the land targets of dynamic "occupation-replenishment" balance of coal village relocation are as follows :within enclosed space of coal mining, phased relocation is applied to the relocation of proposed villages (each period is generally five years). "Occupation first replenishment later" is adopted in the first phase. It means that the right land not affected by mining subsidence is expropriated as new villages.And relocation is proceeded in the villages severely damaged and more urgent to move.Then land consolidation and land reclamation in old village sites should be finished in time to add to the target area that new villages cover; In and after the second phase, the approach"replenishment first occupation later"is adopted. Using the reclaimed land of the former period as "replenishment first" land. Thus the proposed villages relocate as the concept of "occupation later". Land consolidation and land reclamation in old village sites should be finished as well,the result of which contributes to the "occupation first" land for the relocation in next phase. These two processes scroll sequentially. The land covered in first phase can be construction land or cultivated land. If it is construction land, the target of replenishment land in the final phase is construction land.But if it is cultivated land, the target is cultivated land. And cultivated land is calculated with "occupation-replenishment" balance calculation method in order to achieve the balance of quality.

"occupation first replenishment later" stage is mainly used to meet the land indicators. As the principle which requests that the area covered by new villages can not be larger than that covered by old villages, the land in old villages is consolidated and reclaimed to add to the land new villages covers. If there is surplus land, the land can be used as replenishment land in the "replenishment first occupation later" phase; If replenishment land indicators cannot balance the occupation land indicator, the factors that influence occupation land and replenishment land in new villages are necessary to be regulated so that the desired goal can be achieved. In "replenishment first occupation later" period, it is mainly the surplus part of "occupation first replenishment later" period that is contributed to "replenishment first" indicators. And the indicators is used to replace the indicators of occupation land in new villages. Then the land in old village sites is consolidated and reclaimed to be used as post occupation land of new villages or village sites. Occupation land in new villages, taking the construction of new countryside and rural residential land consolidation into account, makes land use indicators scroll. 
Target of coal villages' relocation mainly contains two areas. One is to ensure the vital interests of farmers, and maximize the relocation of construction area in each phase. That is to say, in order to facilitate the residents living, it aims to maximize per capita construction land and minimize the number of floors; the other is to ensure that the reclamation area is bigger than new village area, to achieve "occupation--replenishment" balance, and to maximize the surplus land. The two goals are expressed as z1, z2 as follows:

$$
\begin{aligned}
\operatorname{Max}_{1} & =\sum_{i=1}^{n}\left(R_{i} \times S_{i} \times \frac{1}{L_{i}}\right) \\
\operatorname{Max}_{2}= & \sum_{i=1}^{n}\left(A_{i} \times K_{i}-R_{i} \times S_{i} \times \frac{1}{L_{i}}\right)
\end{aligned}
$$

In these formulas, $R_{i}$ is the population of proposed relocation in phase $I_{\text {. }} S_{i}$ is the construction land area per capita of relocation to new village in phase $\mathrm{I}_{\text {. }} \mathrm{L}_{\mathrm{i}}$ is the number of new village floor in phase $\mathrm{I}$. $A_{i}$ is the old village area of the proposed reclamation in phase $I . K_{i}$ is the reclamation rate in phase $I$.

Due to the contradiction which is a reciprocal relationship between construction target and surplus target, a general objective function is used to measure the pros and cons of number of relocation optimization scheme. This study sets up the weights of the construction area target and the surplus area target, and calculates the average weight of the two as the overall relocation optimal goal, represented by the following formula:

$$
\operatorname{Max} Z=P_{1} \times Z_{1}+P_{2} \times Z_{2}
$$

In the formula, $\mathrm{P}_{1}, \mathrm{P}_{2}$ are the weight of overall optimal target and partial optimal target. $\mathrm{P}_{1}+\mathrm{P}_{2}=1$. The weighted value which measure the two goals make the issue of multi-objective problem into a single goal.

According to dynamic "occupation-replenishment" balance theory, the relocation of villages should satisfy the following restrictions:(1)The area reclaimed per phase --replenishment land area--should be lager than the area of post occupation land in new villages. The final total area of reclaimed replenishment land should be larger than the sum of the occupation land area of new villages. That is to say, the amount of surplus of land must be at least enough to achieve " occupation-replenishment" balance; (2)National rural relocation policy should be taken into account. In order to protect the ordinary people's interests, the limitations of the construction land area Per Capita and the number of floors in new villages should be formulated; (3)There are two main kinds of reclamation methods : traditional reclamation and dynamic reclamation that means mining and reclamation are concurrent. Traditional reclamation costs little but in a low reclamation rate. Dynamic reclamation is with a higher rate, but a higher cost. According to the above theoretical description, restrictions on relocation of coal village are established with the following formula:

$$
\begin{gathered}
f_{1} \geq R_{2} * S_{2} * \frac{1}{L_{2}} \quad f_{2} \geq R_{3} * S_{3} * \frac{1}{L_{3}} \ldots \ldots \begin{array}{c}
\sum_{\mathrm{i}=1}^{\mathrm{n}} A_{i} * F_{i}>\sum_{\mathrm{i}=1}^{\mathrm{n}} R_{i} * S_{i} * \frac{1}{L_{i}} \\
L_{i}=1,2,3,4,5 \\
85<S_{i}<90
\end{array} \\
K_{\mathrm{i}}=\left\{\begin{array}{c}
K_{\text {Traditional }}, \sum_{i=1}^{n} A_{i} * K_{\text {Traditional }}>R_{i+1} * S_{i+1} * \frac{1}{L_{i+1}} \\
K_{\text {Dynamic }}, \text { else }
\end{array}\right.
\end{gathered}
$$

In the formula, $f_{i}$ represents the total area of land reclaimed in phase $i ; R_{i}$ means the number of the relocation population in phase $\mathrm{i}$; $\mathrm{S}_{\mathrm{i}}$ is area of construction land per capita; $\mathrm{L}_{\mathrm{i}}$ is the number of floors in phase $\mathrm{i} ; \mathrm{K}_{\mathrm{i}}$ is the way of reclamation in phase i,including traditional reclamation and dynamic reclamation; $K_{\text {traditional }}$ and $K_{\text {dynamic }}$ are reclamation rates in these two ways; $A_{i}$ is the proposed reclamation area in phase $\mathrm{i}$. 


\section{PSO Algorithm for Optimization of Coal Village Relocation Plan}

The main idea of PSO is to simulate the birds' predation behavior. First of all, it generated a set of particles randomly, in which each particle represents a solution of optimization problem. Then it adjusts the position of particles and optimize the particle. Finally it regards the convergence of particle swarm optimal particle as the final result. Major component of PSO is particle, particle velocity and update of the particle location.

The key to using particle swarm algorithm for solving the matter of villages' relocated number is setting particles and particle velocity correctly. Each particle in the particle swarm algorithm corresponds to a problem solution. The scheme of optimizing the quantity of coal village relocation is to determine the construction land area per capita, the number of floors, and selection of reclamation (traditional reclamation or dynamic ), so setting the particle should also includes these factors. In the present study, the particle is represented by $X_{\mathrm{k}}=\left(L_{\mathrm{i}, \mathrm{k}} 、 R_{\mathrm{i}, \mathrm{k}} 、 M_{\mathrm{i}, \mathrm{k}}\right)$, representing the $\mathrm{i}$ of the k-th particle per capita floor space, the number of relocation, reclamation mode. The size of the particle swarm which is the number of particles is represented by $\mathrm{d}$, in which $\mathrm{j}$-th particle is history optimal solution $\mathrm{P}_{\mathrm{j}}$, and throughout the whole history of particle swarm optimal solution is $\mathrm{P}_{\mathrm{gd}}=\operatorname{Max}\left(\mathrm{P}_{1}, \mathrm{P}_{2}, \ldots, \mathrm{P}_{\mathrm{d}}\right)$.

Particle velocity is determined by three parts: the speed of a moment before of particle, the distance between the current location of particle $\mathrm{J}$ and the optimal position, as well as the distance of particle $\mathrm{J}$ and the optimal solution of particle swarm in the whole history. The formula is expressed as follows:

$$
\begin{aligned}
& V_{j, d}^{t+1}=w^{*} V_{j, d}^{t}+c_{1} * r_{1}\left(P_{j, d}^{t}-X_{j, d}^{t}\right)+c_{2} * r_{2}\left(P_{g, d}^{t}-X_{g, d}^{t}\right) \\
& X_{j, d}^{t+1}=X_{j, d}^{t}+V_{j, d}^{t}
\end{aligned}
$$

$V_{j, d}^{t+1}$ represents the speed of d-th component of the $\mathrm{j}$-th particle velocity at time $\mathrm{t}+1$. W is the inertia factor. $\mathrm{c}_{1}, \mathrm{c}_{2}$ are learning factors. $\mathrm{r}_{1}, \mathrm{r}_{2}$ are random numbers between $0-1 . P_{j, d}^{t}$ represents the optimal solution of current particle in history. $P_{g, d}^{t}$ is the optimal solution of particle swarm in the whole history.

As in particle numbers of floors are discrete, we should improve the speed of particles in the above equation. The formula is expressed as follow:

$$
V_{j, L}^{t+1}=\operatorname{Round}\left\{w^{*} V_{j, L}^{t}+c_{1} * r_{1} *\left(P_{j, L}^{t}-X_{j, L}^{t}\right)+c_{2} * r_{2} *\left(P_{g, L}^{t}-X_{g, L}^{t}\right)\right.
$$

The above formula, the round is rounded integer arithmetic. After improvement, the formula ensures the velocity of the number of floors $L$ component of the particle as an integer.

Iterative termination conditions: optimization meets certain objective function value or the number of iterations threshold $\mathrm{T}$.

Steps of optimization of PSO algorithm to coal villages' dynamic balance are as follows: (1) Generated d particles randomly at the start of operation of program, which generate $d$ solutions. To make sure the correctness of the particles, we should consider the limitations in randomly generation; (2) Calculate the certain objective function value of these particles, elect the maximal particle of the objective function value, and record as the optimal particle in present generation;(3)Determine whether the algorithm is terminated. If it is, exit directly and output the optimal particle as the final optimization. If it don't meet the termination conditions, calculate the velocity of each particle velocity of each component, and adjust the position of the particles according to the particle velocity, generating a new generation of particles. (4) Calculate the objective function value of the new generation particle, rank, and record the optimal position in history and the optimal solution of particle swarm in the whole history of each optimal. (5) Determine whether the algorithm is terminated again. Keep this kind of iteration calculation until it meets the exit criteria. Output the optimal particle as the optimal solution of relocation number of coal villages. 


\section{The Application Example}

According to the regulation of the number of coal village relocation and the requirement of PSO algorithm, we will use instance validation of the relocation of coal village in Longgu Mining. First of all, we will divide moving batches, and then collate respectively the affected village areas of move batches and the population to move. According to the reclamation experience of Heze and related documents, the traditional reclamation rates and the concurrent mining and reclamation rates are as follows: 0.4738 and 0.7144 . In accordance with the requirement of this area, we set global target weight of the regional and local target weights as $0.5, \mathrm{c}_{1}=\mathrm{c}_{2}=1, \mathrm{w}=0.4$, the population size of particle swarm as D, the number of iterations as 100 . The simulation experience was informed that after 100 times' iteration the result will become stable. Through computing, the output is as follows :

Table 1 relocation planning optimization results

\begin{tabular}{ccccc}
\hline Moving batches & $\begin{array}{c}\text { The proposed } \\
\text { construction land area } \\
\text { per capita }\left(\mathrm{m}^{2}\right)\end{array}$ & $\begin{array}{c}\text { Recommended } \\
\text { number of } \\
\text { floors }\end{array}$ & $\begin{array}{c}\text { The village } \\
\text { covers area } \\
\left(\mathrm{m}^{2}\right)\end{array}$ & $\begin{array}{c}\text { The } \\
\text { proposed } \\
\text { reclamation } \\
\text { methods }\end{array}$ \\
\hline "twelve-five" & 97.04 & 2 & 2190000 & Traditional \\
"thirteen-five" & 95.68 & 3 & 495333 & Traditional \\
"fourteen-five" & 98.19 & 4 & 892913 & Dynamic \\
\hline
\end{tabular}

Dynamic "occupation-replenishment" balance theory doesn't need to pay for land reclamation and land use of new construction, doesn't take up the annual plan of agricultural land, exempts troubles in land exploration of mining enterprises, radically solves the difficulties of the land exploration of mining enterprises, tedious procedure of land expropriation, time-consuming, influence of the normal production of mine. We can see from the final result that the surplus of arable land is $41316.66 \mathrm{~m}^{2}$, supplementary food production is greater than the loss, capacity increase of agricultural land increases without reducing, and compared to the traditional "first occupation" method, the third period of the research area will explore at least 5,531 mu of land.

\section{Conclusion}

First is the systematic analysis of the "occupation-replenishment" equilibrium theory, especially from the principle, content and institutional system. From traditional coal village "occupation-replenishment" problems, we can discover shortcomings, and we can explore a new targeted "occupation-replenishment" land theory. Through this, we can not only to meet the balance of "occupation-replenishment" in quantity and quality of land, and will be able to surplus out land targets in an enclosed space in theory.

Second is the establishment of a dynamic " occupation-replenishment" equilibrium theory of particle swarm optimized model for relocation of coal villages. Within the scope of the restrictions, it can not only optimize the relocation of construction land area per capita, the number of floors and the reclamation methods, but also maximize the goal of surplus land and construction land per capita comprehensively.

\section{References}

[1] Yaoqi Yang ,Wu Xiao ,Yu Yang ,Pengfei Wang. The relocation mode of Coal villages preferred based on AHP and Fuzzy Evaluation[J]. Jiangsu Agricultural Sciences,2013,10:376-380. [In Chinese]

[2] Runqiu Liu . Land Transfer balance : typical model and system flaw[J]. Social science research,2011,04:41-45. [In Chinese]. 
[3] Li Huang,Xiaoshun Li,Yunjia Wang,Yongfeng Li,Futian Qu. Theoretical analysis and validation of mining-under village relocation[J]. China Coal,2013,05:5-10+70. [In Chinese].

[4] James Kennedy,Russell Eberhart.Particles swarm optimization.IEEE,1942-1948,1995

[5] Lin Zhang,Fengrong Zhang,Yongsen Xue,Liangzheng Yan. Forecast in the Balance between Occupation and Complementarity of Cultivated Land by Provinces in China[J]. Resources Science,2007,06:114-119. [In Chinese].

[6] Youyuan Liang. In the New Era Research and Application of mining subsidence area of the village removal policy[J]. Coal Science and Technology,2011,04:46-48. [In Chinese]. 